\title{
LARGE SCALE TESTS ON FORESHORE EVOLUTION DURING STORM SEQUENCES AND THE PERFORMANCE OF A NEARLY VERTICAL STRUCTURE
}

Riccardo Briganti ${ }^{1}$, Rosaria Ester Musumeci ${ }^{2}$,Jentsje van der Meer ${ }^{3}$, Alessandro Romano ${ }^{4}$, Laura Maria Stancanelli ${ }^{5}$, Matthias Kudella ${ }^{6}$, Rizki Akbar ${ }^{7}$, Ryard Mukhdiar ${ }^{8}$, Corrado Altomare ${ }^{9}$, Tomohiro Suzuki ${ }^{10}$, Paolo De Girolamo ${ }^{11}$, Giulia Mancini ${ }^{12}$, Giovanni Besio ${ }^{13}$, Nicholas Dodd ${ }^{14}$, Stefan Schimmels ${ }^{15}$

\begin{abstract}
This work presents the results of an experimental investigation on the effects of a sequence of storms on wave overtopping at a nearly vertical battered seawall at the back of a sandy foreshore. The experiments were carried out in the Large Wave Flume (GWK) at Leibniz Universität Hannover (Germany), as part of the research project ICODEP (Impact of Changing fOreshore on flood DEfence Performance), within the European Union programme Hydralab+. The layout consisted of a 10/1 battered seawall and a natural sandy foreshore with an initial 1:15 slope. The beach sand had a nominal diameter of $0.30 \mathrm{~mm}$. Three storm sequences were simulated, where each consisted of three individual storms. Each storm was divided into six steps in which the wave conditions and still water level were varied to represent the peak of an actual storm. The six sea states were based on a JONSWAP spectral shape, with wave heights roughly between $0.6 \mathrm{~m}$ and $0.8 \mathrm{~m}$. Two still water levels were tested. For the central two steps the level was such that the freeboard was only $0.14 \mathrm{~m}$ and almost all waves were overtopping. In the remaining steps low still water levels were employed, leaving a narrow swash zone. Two storm profiles were considered, the first one with a lower level of energy and the second one with a higher one. These were combined in the three different sequences. All the tested wave conditions were designed to be erosive for the beach, with no recovery in between. Each sequence started from a plain beach configuration and the beach was not restored in between storms. The measurements included waves, pressure and forces, sediment concentrations and flow velocity together with overtopping. The profile of the beach was measured after each sea state tested.
\end{abstract}

Keywords: wave overtopping, coastal flooding, coastal structures, storm sequences, morphodynamics, seawall, beach foreshore,

\section{INTRODUCTION}

Coastal flood defence structures are often found at the back of a natural beach (e.g. Suzuki et al., 2017; Doorslaer et al., 2017) During storms the evolution of the foreshore influences the performance of the structure; in turn, the presence of the structure influences the evolution of the foreshore. For these reasons, these structures should be regarded as components of composite natural/engineered defence. These have an increasingly prominent role in coastal management because of ageing coastal structures, which prompt the need to integrate them with ecosystem-based solutions (Temmerman et al., 2013). One aspect that is central for this type of coastal defences is that the pre-storm beach profile has an impact on the defence response to the wave forcing. This is particularly important when storms arrive at intervals too short to allow full recovery of the beach. Understanding the influence of sequences of storms on the system allows better modelling and design of composite coastal flood defences.

Note that sequences of storms separated by intervals that are shorter than recovery time of the beaches are often referred to as clusters. However, this term implies that storms inter-arrival times do not follow the Poisson distribution as found for the Mediterranean Sea by Besio et al. (2017). Here the response of the beach is studied regardless of the statistical property of the forcing, hence only the general term sequence will be used throughout the paper for this phenomenon.

Existing investigations on storm sequences analyse natural beaches and very little research is available on

\footnotetext{
${ }^{1}$ Department of Civil Engineering, University of Nottingham, United Kingdom

${ }^{2}$ Department of Civil Engineering and Architecture, University of Catania, Italyy

${ }^{3}$ IHE Delft Institute for Water Education, The Netherlands

${ }^{4}$ Department of Civil, Building and Environmental Engineering (DICEA), "Sapienza" University of Rome, , Italy

${ }^{5}$ Department of Civil Engineering and Architecture, University of Catania, Italy

${ }^{6}$ Forschungszentrum Küste (FZK), Hannover, Germany

${ }^{7}$ IHE Delft Institute for Water Education, The Netherlands

${ }^{8}$ IHE Delft Institute for Water Education, The Netherlands

${ }^{9}$ Hydraulics Research, Belgium

${ }^{10}$ Flanders Hydraulics Research, Belgium

${ }^{11}$ Department of Civil, Building and Environmental Engineering (DICEA), "Sapienza" University of Rome, , Italy

${ }^{12}$ Department of Civil Engineering, University of Nottingham, United Kingdom

${ }^{13}$ Department of Civil, Chemical and Environmental Engineering (DICCA), University of Genoa, Italy

${ }^{14}$ Department of Civil Engineering, University of Nottingham, United Kingdom

${ }^{15}$ Forschungszentrum Küste (FZK), Hannover, Germany
} 
the behaviour of engineered beaches. The focus of the existing works is to understand if the cumulative impact of a sequence of storms, is higher than the sum of the average impact of the individual events, as identified in the review by Sénéchal et al. (2017) to which the reader is referred for a comprehensive overview of the literature on this topic. In these studies the role of offshore sand bars was found to be crucial. For example, the impact of lower energy storms in a sequence is amplified by the decay of offshore bars caused by previous more energetic storms (Castelle et al., 2007). When no bar is present, a rapid erosion occurs and the bar quickly develops, subsequently the beach tends to an equilibrium, which makes the role of later storms in a sequence less important (Vousdoukas et al., 2012).

The enhancement of the impact of storms of moderate intensity found for natural beach opens to the possibility that the same can happen for coastal defences. This occurrence has never been investigated in depth. The project ICODEP (Influence of foreshore evolution on COastal DEfence Performance) aims at filling this gap in research. Wave overtopping at a composite flood defence during a sequence of storms was investigated with a large scale laboratory test. The flood defence was made of a sandy foreshore and a steep hard structure, representative of a seawall commonly found in coastal areas across the world. The tested storms did not allow recovery in between their arrival. The experiments were carried out at the Large Wave Flume (GWK) at Leibniz Universität Hannover (Germany). It is known that experiments on large scale are the only ones capable of minimising the scale effects for sediment transport, foreshore evolution, and sometimes for wave overtopping (see EurOtop, 2016). Large flumes, such as the GWK and Delta Flume, were built to cope with morphodynamic scale effects and the possibility of their occurrence in wave overtopping in the presence of long foreshores were reported by Franco et al. (2009) and included in EurOtop (2007) and EurOtop (2016).

The experimental layout (see Fig. 1) consists of a 10/1 sloped seawall and a sandy foreshore with an initial $1 / 15$ slope. The natural sand of the beach has a nominal diameter $\left(D_{50}\right)$ of $0.30 \mathrm{~mm}$. The reference frame used in this work has the origin of $x$ at the neutral position of the wave paddle and the origin of $z$ is set at the bottom of the flume at the toe of the beach, which is at $x=161.9 \mathrm{~m}$. The $y$ coordinate origin is located on the instrumented wall of the flume (see Fig. 2). The coordinates of crest of the seawall are $x=240.93 \mathrm{~m}$ and $z=5.5 \mathrm{~m}$.

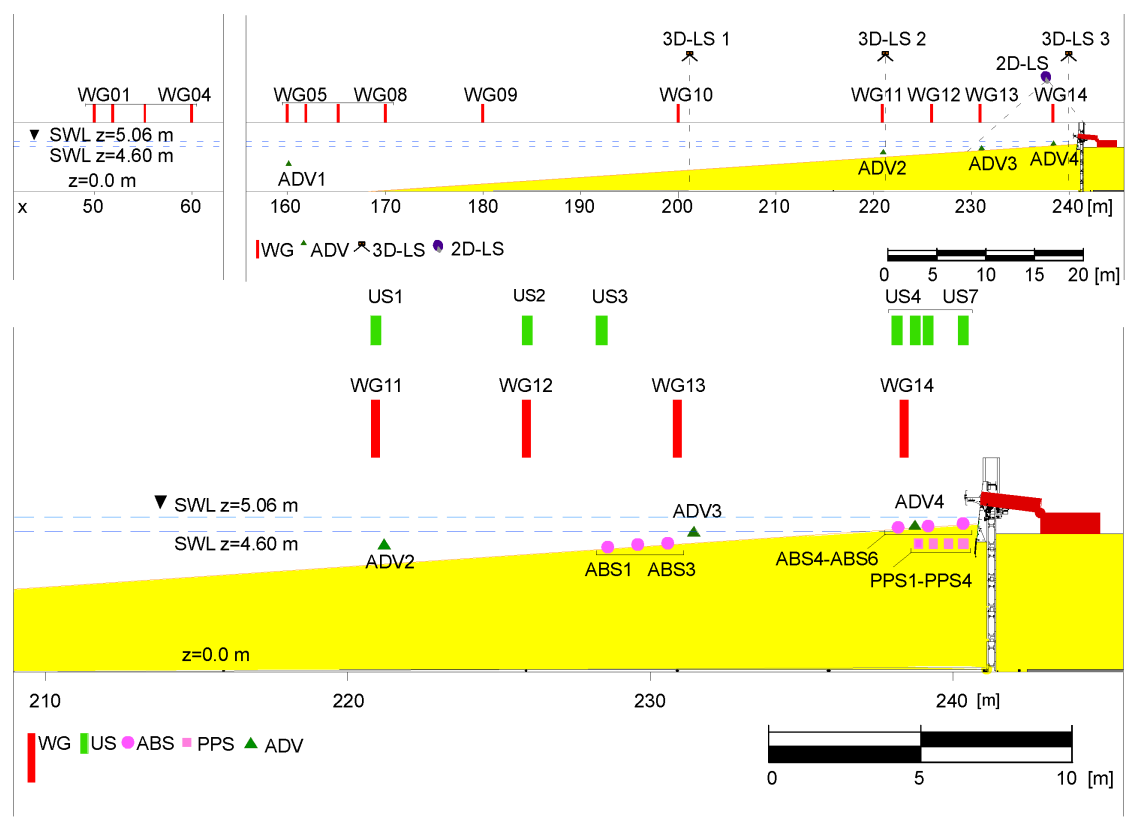

Figure 1: Layout of the ICODEP engineered beach and instruments. Upper panel: overview of the flume. Lower panel: close up on the structure.

The model of the 10/1 sloping wall (see Fig. 2) was made of a steel plate reinforced with plywood bars on the back and supported by a steel frame. This is anchored to the flume walls by two vertical rails. The 
structure toe at the beginning of each sequence is located at $x=240.86 \mathrm{~m}$. Behind the steel seawall a vertical impermeable wall extended down to the bottom of the flume, in order to create an hydraulic disconnection for the groundwater flow between the beach and the sand at the back of the wall. The structure was buried in the sand for a depth of $0.9 \mathrm{~m}$ with respect to the initial level of the beach at the toe. Fig. 1 shows the positions of all the instruments along the foreshore, while Fig. 2 shows the seawall and all the instruments that are installed on it.

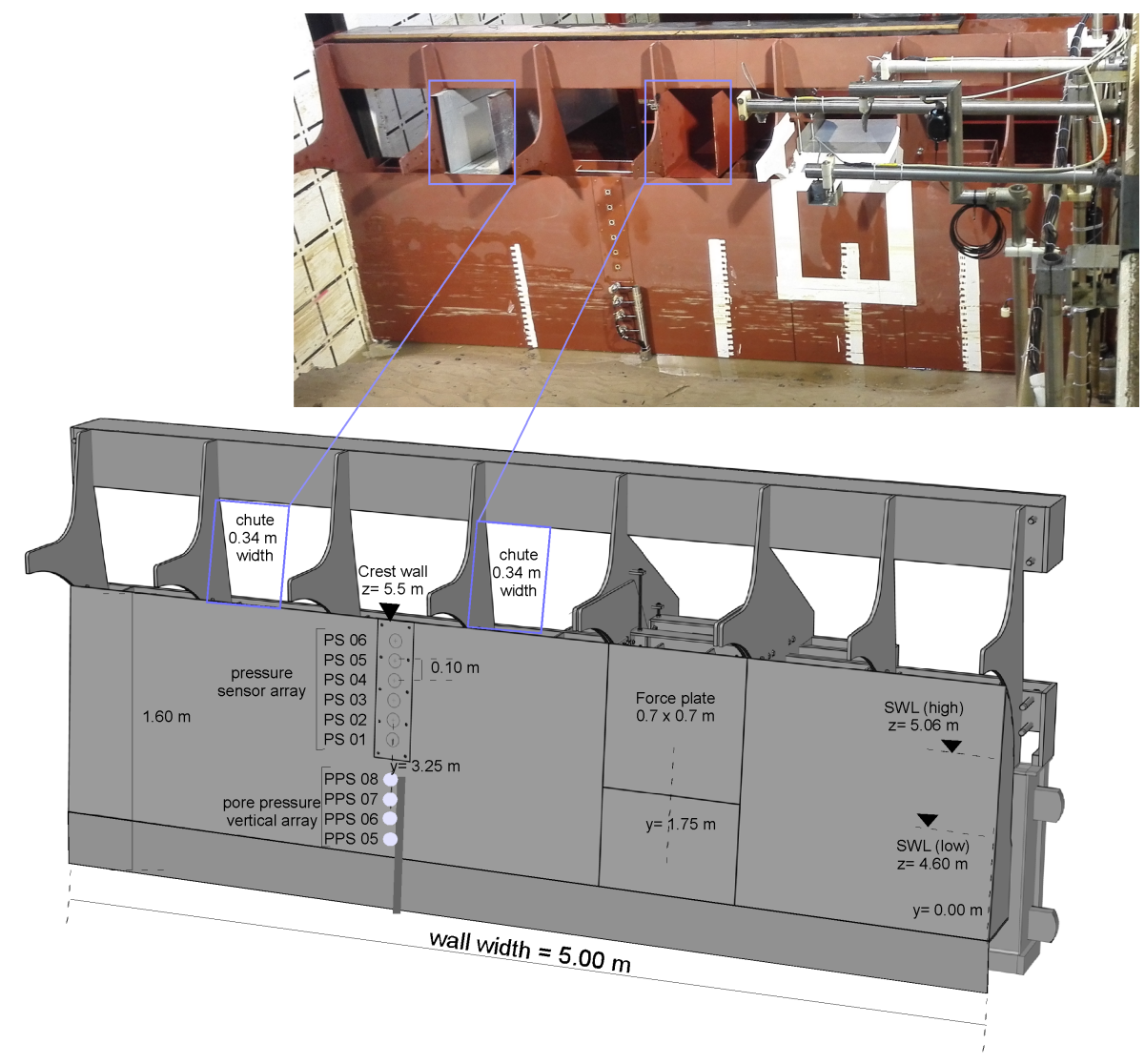

Figure 2: 3D view of the tested seawall with the instruments installed.

\section{LABORATORY TESTS}

Hydrodynamic test conditions

Three different sequences of storms were tested, these are referred to as sequences $C 1, C 2$, and $C 3$. Two storms, with different energy levels, referred to as storms $S 1$ and $S 2$, were combined to form each sequence (see Table 1). $S 2$ is the most energetic between the two storms.

The tested wave conditions have been chosen to be representative of those of typical storms in macrotidal Northern European seas. However, in large scale laboratories, it is not feasible to replicate a sequence of complete storms, hence the focus was on the peak of each storm and the simultaneous peak of the sea levels. Each storm profile was divided into six sea states, referred to as sea states $T 1$ to $T 6$. They were generated using the JONSWAP spectrum with a shape factor $\gamma=3.3$, consistent with the capability of the wave generator at the GWK. The duration of each sea state is $D_{s}=32$ minutes. Fig. 3 shows the time history of both the significant wave height $\left(H_{m 0}\right)$ and Still Water Level (SWL) conditions tested. The sequence of individual waves for each sea state is kept the same throughout the tests, in order to remove the variability due to the particular sequence of waves at the boundary (Romano et al., 2015, Williams et al., 2014). Two SWL conditions were applied during each storm; these were the same for storm $S 1$ and $S 2$. $T 3$ and $T 4$ were always tested with the SWL at $5.06 \mathrm{~m}$ from the bottom of the flume (referred as high SWL conditions hereinafter), and the rest of the storm was tested with the SWL at 4.60 m (low SWL hereinafter). 


\begin{tabular}{cccc} 
Sequence & Position & Storm profile & Initial beach profile \\
\hline $\mathrm{C} 1$ & 1 & $\mathrm{~S} 2$ & Plane slope $1 / 15$ \\
& 2 & $\mathrm{~S} 2$ & As evolved due to previous S2 \\
& 3 & S2 & As evolved due to previous S2 \\
\hline $\mathrm{C} 2$ & 1 & $\mathrm{~S} 2$ & Plane slope $1 / 15$ \\
& 2 & $\mathrm{~S} 1$ & As evolved due to previous S2 \\
& 3 & $\mathrm{~S} 2$ & As evolved due to previous S1 \\
\hline $\mathrm{C} 3$ & 1 & $\mathrm{~S} 1$ & Plane slope $1 / 15$ \\
& 2 & $\mathrm{~S} 2$ & As evolved due to previous S1 \\
& 3 & $\mathrm{~S} 1$ & As evolved due to previous S2 \\
\hline \hline
\end{tabular}

Table 1: Storm sequence and initial bed conditions for the three sequences.
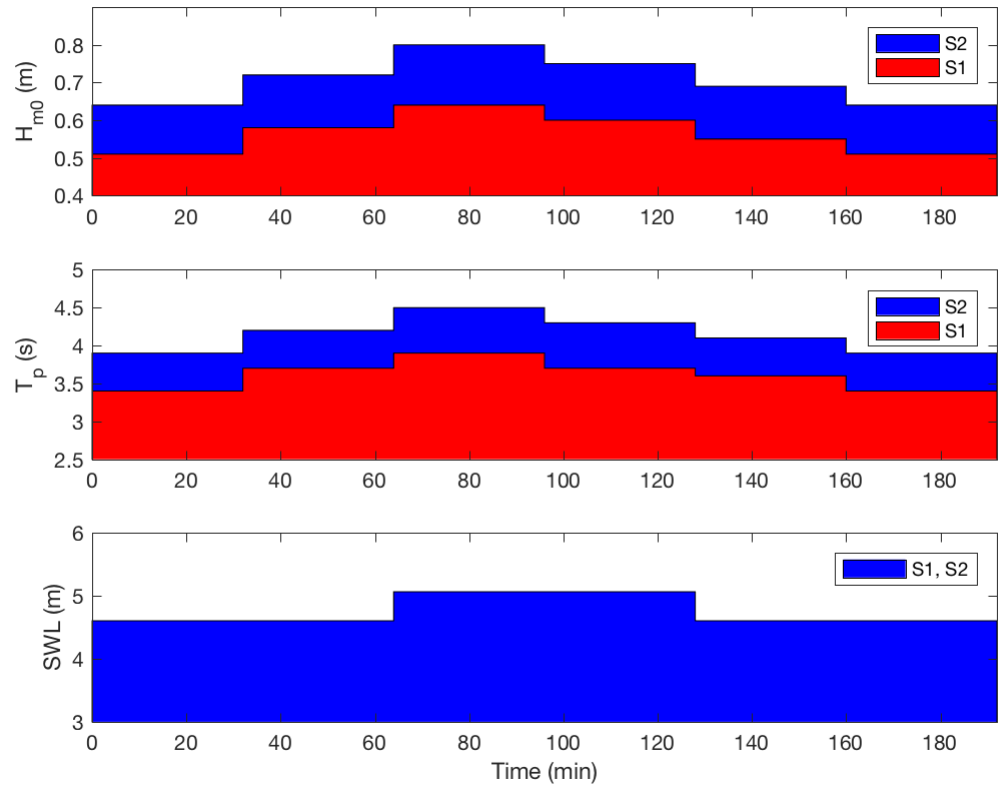

Figure 3: Characteristics of the simulated storms. Upper panel: $H_{m 0}$; middle panel: $T_{p}$; lower panel: $S W L$

As shown in Fig. 3 in both $S 1$ and $S 2, H_{m 0}$ increases from the first to the second segment of the storm ( $T 1$ and $T 2$ ) at low SWL conditions, it reaches a maximum at $T 3$ in high SWL conditions and decays afterwards from $T 4$ to $T 6$. The coincidence of maximum $H_{m 0}$ and maximum SWL was chosen because maximum overtopping is expected to occur when high tide and the maximum significant wave height occur at the same time. This was the case of the storm on the east coast of England (U.K.) that occurred from $5^{\text {th }}$ to $6^{\text {th }}$ December 2013, as discussed in Dissanayake et al. (2015), when the peak storm wave height coincided with high-water during spring-tide.

$S 1$ and $S 2$ have been combined into three sequences (see Table 1). Each sequence started from a 1/15 plain slope, while the beach profile after each storm was the initial one of the following storm. In $C 1$ the repetition of the most energetic storm was tested, in order to measure the effects of previous bed evolution on the same storm. Conversely, $C 2$ and $C 3$ were meant to test the effects of storms of different energy levels alternating in a sequence. Note that no recovery was made in between storms.

In this paper each storm sea state will be referred using the two characters codes in a sequence, separated by "-", in which first the sequence is indicated, then a number from 1 to 3 is used to identify the position of the storm in the sequence, followed by the codes for the storm and that of the sea state. For example $C 3-2-S 2-T 4$, indicates sea state $T 4$ of the storm $S 2$ that was tested as second in sequence $C 3$. 
Beach profile measurement

The beach profiles were obtained by a combination of data gathered by a mechanical wheel profiler, a Sick LMS291-S14 Two-dimensional time of flight laser scanner (2D-LS hereinafter), and a Faro Focus 20/120 three-dimensional laser scanner (3D-LS hereinafter). The mechanical beach profiler was run to measure the initial planar sloping beach and the profile after each sea state condition, from $x=100 \mathrm{~m}$ up to about $x=240.3 \mathrm{~m}$, with a spatial resolution of $\Delta x=0.25 \mathrm{~m}$. Point clouds of the bottom have been obtained by means of the 3D-LS, which was moved at three measuring stations along the flume (see upper panel of Fig. 1) and calibrated using the proprietary Faro software and the known coordinates of several markers in the lab. The resolution of the point clouds was $O(0.01 \mathrm{~mm})$. 3D reconstructions of the entire sandy bottom $(x>190 m)$ were obtained both at the beginning and at the end of each storm sequence, when the flume was drained before beach reshaping. Additional 3D-LS measurements of the region close to the wall, $231.5 m<x<241.0 m$, were obtained in dry conditions in the upper part of the beach, i.e. at the end of every even sea state, except for $T 3$, when a dry condition was not reached. In particular, the beach profile was extracted from the 3D point cloud by spanwise averaging the points gathered within a central stripe, $2.49 m<y<2.51 \mathrm{~m}$. 2D-LS measurements running continuously during each test provided information on the foreshore evolution in proximity of the wall as well as a further measurement of the moving free surface. These measurements were calibrated using three metallic poles located at the center of the measurement region. The coordinates of the poles were known with topographic precision. The 2D-LS had an angle resolution of $0.1667^{\circ}$ and a measuring angle of about $115^{\circ}$. The measuring range was $228.5 m<x<243.5 m$. Due to physical constraints, the mechanical wheel profiler could not reach the toe of the wall, located at about $x=240.9 \mathrm{~m}$. The data on the near-wall bed profile obtained by the 3D scanner, for the initial condition and at the end of sea states T2, T4 and T6 were used to complete the beach profile for the last $60 \mathrm{~cm}$. For sea states T1 and T5 the data of the 2D scanner were used for the same purpose. Due to the presence of water, it was not possible to have data on the bottom morphology at the toe of the wall at the end of all the sea states T3, in high SWL conditions, and for some of the T5 sea states, as the scour was flooded notwithstanding the fact that the SWL was lowered. Analysis of the data revealed that the profiles recovered by the wheel profiler were systematically lower, $O(2 \mathrm{~cm})$, than those recovered by the calibrated 2D and 3D laser scanners. On the other hand, the latter ones matched fairly well with each other. The mismatch is probably due to the burial of the wheel of the profiler in the sandy bottom. Therefore a correction was made of each bed profile measured mechanically. The complete beach profiles were then obtained by joining the offshore part of the wheel profiler data and onshore part of the 3D/2D scanners data. Finally, the scour evolution was also monitored by the same video camera used for wave overtopping. To this end, four rulers are attached to the sloping wall, in order to have a visual reference of the scour depth.

\section{Overtopping measurement}

A gravimetric overtopping tank with a volume of approximately $1.40 \mathrm{~m}^{3}$ was used to collect the volume of water due to overtopping. The mechanism consisted of two tanks (inner and outer) and a connection to the crest of the wall by means of at least one chute. The inner tank was placed on four force transducers (the positions of which are indicated in the additionally provided spreadsheet) that measured its weight during the tests. The outer tank provided a dry area around the inner tank to put the sensors. Also, a pumping system was used to pump the collected water during the experiment, which was activated manually, with the trigger signal of the pump being recorded to identify the intervals of usage. The chute $(0.34 \mathrm{~m}$ wide $)$ was placed at the inner edge of the crest of the middle of the wall, connecting the structure and the inner tank. The number of chutes used depended on the water level. During low SWL sea states, two chutes were used, as opposed to high SWL conditions, in which only one was used (with the only exception of storm $C 2-1-S 2-T 3$ in which two chutes were used).

A pressure transducer (PS 07) was installed at the crest of the sloping wall, in the central chute, in order to make an estimation of the number of wave overtopping events. Furthermore, two synchronised video cameras recorded the overtopping events. The first camera was located at $x=225 \mathrm{~m}$, at the level of the aisle along the flume, and the second one located close to the roof, at $x=238 \mathrm{~m}$. Finally, in order to avoid problems due to the presence of the top beam of the structure, a plywood panel was installed on top of the beam that directed the entire overtopping volume within the chute. 


\section{Other instruments}

Other sets of instruments were installed to measure forces and pressures on the wall and sediment transport and flow velocity in the surf zone and close to the wall. In order to measure pressures on the wall, an array of six PSs (1 to 6) was installed on the wall (see Fig. 2). The PSs are spaced about $0.1 \mathrm{~m}$ from each other. Besides, forces were measured on the wall using a plate at which 5 load cells were connected (see Fig. 2). Since this paper is focused on the effect of bed mobility on wave overtopping the force plate is only mentioned here.

Sediment transport was measured by two Acoustic Backscattering Sensors (ABS), one located in correspondence of the surf-zone bar and the second close to the structure. Four Acoustic Doppler Velocimeters (ADVs) were used to measure local flow velocity, these were located along the whole active part of the beach. Since the focus of this paper is the interplay between foreshore dynamics and wave overtopping, the measurements of these instruments will be discussed in further work.

\section{EXPERIMENTAL RESULTS}

\section{Morphodynamic evolution of the foreshore}

The foreshore evolution within a storm is studied by analysing the bed change after each sea state with respect to the initial bed profile $\Delta z_{b}=z_{b}\left(t_{e}, s\right)-z_{b}\left(t_{0}\right)$, where $z_{b}$ is the bed level from the bottom of the flume, $\left(t_{e}, s\right)$ is the end time of each sea state $(s=1,2, . ., 6)$ and $t_{0}$ is the start time of each sequence, when the beach had its $1 / 15$ plain slope. The intra-storm evolution of the bed is qualitatively similar in all cases. At the start of the sequence, during $T 1$, a bar started developing and grew in the subsequent sea states. At the same time erosion developed in the region between the bar and the wall, approximatively between $x=230 \mathrm{~m}$ and $x=240.86 \mathrm{~m}$. The evolution close to the structure is more complex as accretion occurred during the first storm of the sequence. During $T 2$ the bar grew and migrated offshore, while the erosion of the region between the bar and the structure increased.

In the two high SWL sea states significant erosion developed near the toe of the structure. Also, it appears that partial backfilling occurred and $\Delta z_{b}$ reached almost zero around $x=236 \mathrm{~m}$ during $T 4$. The backfilling in this region reversed to erosion in the subsequent $T 5$, while partial filling of the scour at the toe of the seawall and continued in $T 6$.

$\Delta z_{b}$ is negative overall close to the structure, however, during high SWL, the morphodynamics of the region between the bar and the seawall is more complex, with deposition occurring just offshore the scour area.

Fig. 4 shows the initial and final profile for the three sequences together with the range of $z_{b}$ reached. Results are consistent for all three sequences and the evolution of the beach can be described by dividing it into four zones. Zone 1 is the ripple region extending approximatively from $x=200 \mathrm{~m}$ and $x=217$ $\mathrm{m}$. Zone 2 is the bar region extending approximatively from $x=217 \mathrm{~m}$ and $x=230 \mathrm{~m}$ in $C 1$ and $C 3$; here the bar formed and migrated offshore during each sequence. The boundary between Zone 2 and 3 is a pivot around which the beach rotated. Zone 3 is characterised by overall erosion with respect to the initial profile, as the figure shows. However, in Zone 3 backfilling occured at high SWL conditions; this could be large enough to establish a secondary bar above the original profile as the results for $C 1$ (panel $a$ of Fig. 4) show. The slope of Zone 3 was milder than the original 1/15 and appears to be almost zero in the upper part of this region in all sequences. This lowered platform formed at the position of the initial shoreline at the lower SWL. This is considered as the boundary with Zone 4. Here both swash motion and scour have an important role in modelling the beach.

\section{Wave Overtopping}

Before analysing the results the methodology used to compute the overtopping rate is discussed. The weight of water, collected by the chutes into the tank, was recorded by four load cells during each test. The sum of the measurement by each load cell gave the total weight of overtopping water. The instantaneous volume of water is obtained by dividing the weight by $\rho g$, where $\rho$ is the water density and $g$ the acceleration of gravity $\left(\rho=1000 \mathrm{~kg} / \mathrm{m}^{3}, g=9.81 \mathrm{~m} / \mathrm{s}\right)$. The data were smoothed using a moving average filter with a window size equal to the nominal wave peak period $\left(T_{p}\right)$ of each experiment.

The pumping system in the overtopping tank was not activated during low SWL conditions when only a few waves were overtopping. Conversely, the pump was activated to keep the level of the water in the tank low for high SWL conditions. An example of wave overtopping data for a high SWL condition is shown in Fig. 5. As seen in the figure, almost all waves were overtopping and it was necessary to activate the pump multiple times in these conditions (tipically 3 to 5 times per sea state). The pump discharge was calibrated 

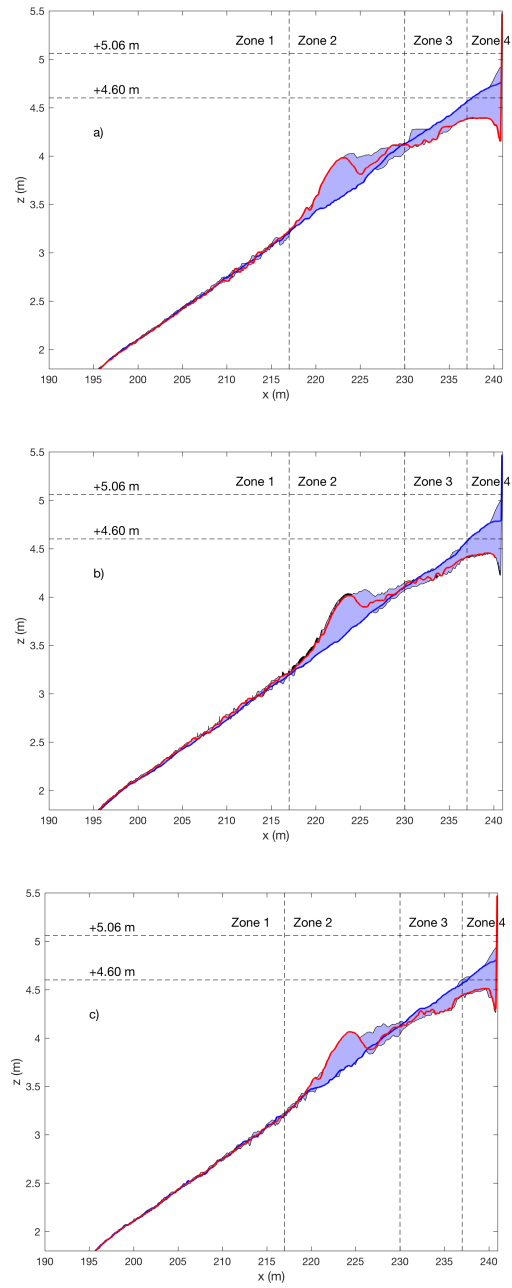

Figure 4: Zones of the beach evolution for sequence. Blue line: initial profile, red line: end profile. The blue shaded area is the range of the bed level at each position. a) $C 1$ b) $C 2$, c) $C 3$.

in a separate set of tests.

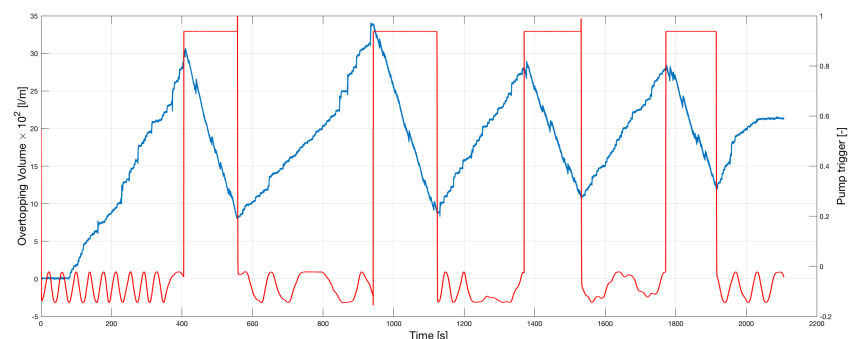

Figure 5: Measured overtopping volume er unit length (blue line) $p$ and pump trigger (red line) for storm $C 1-1-S 2-T 4$.

Two approaches were used to compute the mean overtopping discharge $(q)$ for the experiments. The first approach used the information from the pump; the discharge pumped out was added to the discharge 
computed using the signal from the gravimetric tank, using the relationship:

$$
q=\left(\frac{V_{t}\left(t=t_{\text {end }}\right)-V_{t}\left(t=t_{0}\right)}{W_{c} T_{\text {test }}}\right)+\left(\frac{\sum_{i=1}^{N_{p}} q_{p, i} T_{p, i}}{W_{c} T_{\text {test }}}\right)
$$

Here, $V_{t}$ is the volume of water in the tank, $t$ is time, $t_{0}$ is the start time of the test and $t_{\text {end }}$ the end time, $T_{\text {test }}=t_{\text {end }}-t_{0}$ is the test duration, $W_{c}$ is the width of the chutes used in each test. For the pump, $N_{p}$ is the number of times that the pump was used in a test, $q_{p, i}$ is the discharge of the pump in the $i-t h$ interval of usage, known from the pump calibration curve. $T_{p, i}$ is the duration of the interval of usage. The second approach was to exclude inaccuracy of the pump discharge from the measurement and to compute $q$ only over the time when the pumps were not working, i.e.:

$$
q=\left(\sum_{i=1}^{N_{q}} \frac{\Delta V_{t, i}}{T_{q, i}}\right) \frac{1}{W_{c}}
$$

where $N_{q}$ is the number of intervals within the test in which the pump was not used, $\Delta V_{t, i}$ is the difference in volume of water in the tank for each interval, $T_{q, i}$ is the duration of each of these intervals. Comparison between the results obtained using Eq. (1) with those obtained by Eq. (2), showed that the two methods used are in good agreement, with a maximum percentage difference of $13.11 \%$ for $C 1-2-S 2-T 3$. In two tests, $(C 2-1-S 2-T 3$ and $C 2-1-S 2-T 4)$, only the initial part of the time series, in which the pumps were not use, could be used, as the tanks overflew during the tests even with pumping. This was due to the presence of two chutes and prompted the reduction to one chute only in subsequent high SWL tests. Given the small difference between the results of Eq. (1) and Eq. (2) and the fact that the latter was applicable to all cases, only the results obtained with Eq. (2) will be shown in this work.

The number of overtopping events $\left(N_{o v}\right)$ is an important parameter in assessing overtopping. This was evaluated using the pressure transducer installed in the chute $P S 7$, in conjunction with the overtopping tank measurements, and the video cameras records. The ratio between $N_{o v}$ and the number of incident waves obtained by zero-crossing analysis of the incident wave time series calculated using WG 1-4 is the percentage of overtopping $\left(P_{o v}\right)$. Other authors (e.g. Chen et al., 2016) use the incident time series at the toe of the structure. However, in this case the significant wave breaking on the foreshore, makes the computation of the incident time series with the traditional three gauges waves not accurate. Alternatively numerical methods could be used, but this is beyond the scope of the present paper.

For each storm, three phases are identified, i.e. before the peak ( $T 1$ and $T 2)$, at the peak ( $T 3$ and $T 4)$, and after the peak (T5 and T6). These are highlighted in different colours in Fig. 6. Note that for low SWL conditions overtopping is always caused by only a few waves and it is always three orders of magnitude lower than peak conditions.

The first sea state $T 1$ for each sequence, i.e. that with a plain beach as initial configuration, has always no measurable overtopping. In subsequent storms of the sequences, the same segment shows some overtopping, for both $S 1$ and $S 2$. In $C 1$, in which $S 2$ is repeated three times, for both $T 1$ and $T 2, q$ increases with the position within the sequence. These results show that $q$ varies significantly with the initial configuration of the beach for a given set of hydrodynamic forcing in low SWL. For example in $C 1-1-S 2-T 1$ no wave was overtopping, while in $C 1-3-S 2-T 1$ it was measured $q=0.024$ /s per m with $P_{o v}=4.54 \%$ Similar considerations apply to the post peak results for $q$ (in green in Fig. 6). The variability of $q$ with the initial conditions for the beach is better shown in the two peak sea states of the storm (in blue in Fig. 6 ). In sequence $C 1$, there is a slight monotonic increase in $q$ within the whole sequence. More importantly, in sequence $C 2$, the peak of the second storm $(S 1)$, although of lower energy, shows nearly the same $q$ as the previous $S 2$. If compared with the results of storm $S 1$ as first of sequence $C 3$, the peak of storm $S 1$ as second storm of sequence $C 2$ shows a much higher $q$. For $C 2-2-S 1-T 3 q=8.451 / \mathrm{s}$ per $\mathrm{m}$ compared to $q=5.31 \mathrm{l} / \mathrm{s}$ per $\mathrm{m}$ for $C 3-1-S 1-T 3$. Consistently, in sequence $C 3, q$ for storm $S 1$ as third storm in the sequence, is nearly the double of storm $S 1$ as first. 

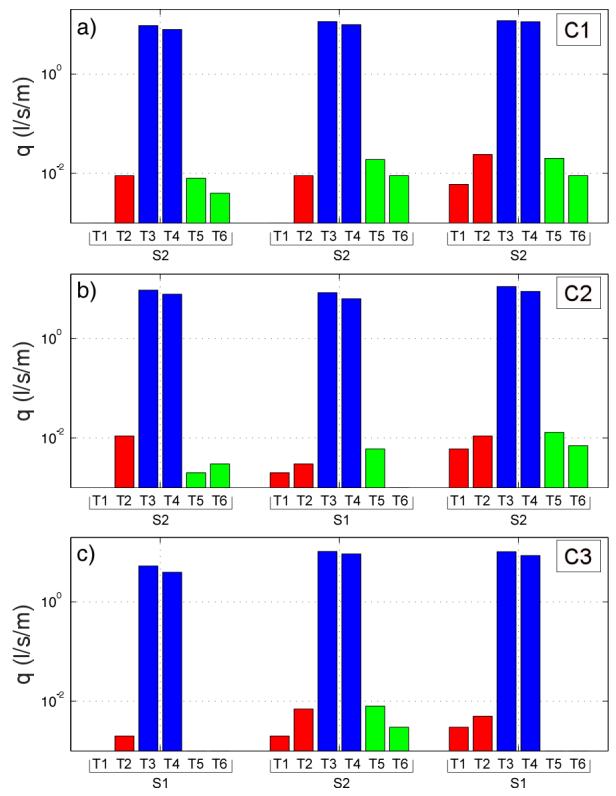

Figure 6: $q$ for all sequences. $a): C 1, b): C 2, c)$ : $C 3$. Red bars: pre-peak conditions ( $T 1$ and $T 2)$, blue bars: peak conditions ( $T 3$ and $T 4$ ), green bars: post-peak conditions ( $T 5$ and $T 6$ )

\section{CONCLUSION}

This work shows that the level of overtopping at seawalls is sensitive to the evolution of the foreshore during sequences of storms. The mechanism that affects the overtopping is the modification of the energy of the waves by the lowering of the beach and the formation of the bar.

The study also shows that response of engineered beaches to storms sequences requires a detailed analysis, since their behaviour differs significantly from natural beaches when sequences of storms are considered. The beach response to wave-seawall interactions in steady conditions has been extensively studied. However, the processes that determine the evolution when the SWL and the waves change within a storm are not sufficiently studied. Moreover, in engineering practice, it is common practice to consider as design conditions, those corresponding to an isolated storm, while this study shows the importance of considering the evolution in time of the beach, and the resulting change in hydraulic performance. Therefore, the next step of this research will be to investigate the behaviour of this type of beaches under cyclic wave and water level conditions in order to understand the processes that determine the erosion and deposition in the identified zones. In particular, the alternate action of swash motion in low SWL and reflection in high SWL conditions on sediment transport and morphodynamics is of great scientific and technical interest.

Furthermore the role of the initial beach configuration challenges existing predictive tools because of the need of knowing the initial beach profile and how this evolves during a storm. Therefore an analysis of existing empirical and numerical prediction tool is a necessary step to support the improvement of natu$\mathrm{ral} /$ engineered coastal defences design.

\section{ACKNOWLEDGEMENTS}

The work was supported by the European Community Horizon 2020 Research and Innovation Programme through the grant to HYDRALAB-PLUS, Contract no. 654110.

\section{References}

G. Besio, R. Briganti, A. Romano, L. Mentaschi, and P. De Girolamo. Time clustering of wave storms in the mediterranean sea. Natural Hazards and Earth System Sciences, 17(3):505-514, 2017. doi: 10.5194/ nhess-17-505-2017. URL http://www. nat-hazards-earth-syst-sci.net/17/505/2017/.

B. Castelle, I. Turner, B. Ruessink, and R. Tomlinson. Impact of storms on beach erosion: Broadbeach (gold coast, australia). Journal of coastal research, (50):534, 2007. 
X. Chen, B. Hofland, and W. Uijttewaal. Maximum overtopping forces on a dike-mounted wall with a shallow foreshore. Coastal Engineering, 116:89-102, 2016.

P. Dissanayake, J. Brown, P. Wisse, and H. Karunarathna. Effects of storm clustering on beach/dune evolution. Marine Geology, 370:63-75, 2015. URL www. scopus . com.

K. V. Doorslaer, A. Romano, J. D. Rouck, and A. Kortenhaus. Impacts on a storm wall caused by nonbreaking waves overtopping a smooth dike slope. Coastal Engineering, 120:93 - 111, 2017. ISSN 03783839. doi: https://doi.org/10.1016/j.coastaleng.2016.11.010. URL http: //www . sciencedirect . com/ science/article/pii/S0378383916302897.

EurOtop. EurOtop - Wave Overtopping of Sea Defences and Related Structures Assessment Manual. Pullen, T. and Allsop, N.W.H. and Bruce, T. and Kortenhaus, A. and Schüttrumpf, H. and van der Meer, J.W. Environment Agency, UK, 2007. URL http: //wWw . overtopping-manual . com.

EurOtop. Manual on wave overtopping of sea defences and related structures. An overtopping manual largely based on European research, but for worldwide application., 2016. URL http://wwW . overtopping-manual.com.

L. Franco, J. Geeraerts, R. Briganti, M. Willems, G. Bellotti, and J. De Rouck. Prototype measurements and small-scale model tests of wave overtopping at shallow rubble-mound breakwaters: the Ostia-Rome yacht harbour case. 56(2)(doi:10.1016/j.coastaleng.2008.03.009):154-165, 2009.

A. Romano, G. Bellotti, R. Briganti, and L. Franco. Uncertainties in the physical modelling of the wave overtopping over a rubble mound breakwater: The role of the seeding number and of the test duration. Coastal Engineering, 103:15-21, 2015. URL wWW . scopus . com.

N. Sénéchal, B. Castelle, and K. R. Bryan. Storm Clustering and Beach Response, chapter 8, pages 151174. John Wiley \& Sons, Ltd, 2017. ISBN 9781118937099. doi: 10.1002/9781118937099.ch8.

T. Suzuki, C. Altomare, W. Veale, T. Verwaest, K. Trouw, P. Troch, and M. Zijlema. Efficient and robust wave overtopping estimation for impermeable coastal structures in shallow foreshores using swash. Coastal Engineering, 122:108 - 123, 2017. ISSN 0378-3839. doi: https://doi.org/10. 1016/j.coastaleng.2017.01.009. URL http://www.sciencedirect.com/science/article/pii/ SQ378383916302435.

S. Temmerman, P. Meire, T. J. Bouma, P. M. Herman, T. Ysebaert, and H. J. De Vriend. Ecosystem-based coastal defence in the face of global change. Nature, 504(7478):79, 2013.

M. I. Vousdoukas, L. P. M. Almeida, and Ó. Ferreira. Beach erosion and recovery during consecutive storms at a steep-sloping, meso-tidal beach. Earth Surface Processes and Landforms, 37(6):583-593, 2012.

H. E. Williams, R. Briganti, and T. Pullen. The role of offshore boundary conditions in the uncertainty of numerical prediction of wave overtopping using non-linear shallow water equations. Coastal Engineering, 89:30-44, 2014. URL www. scopus. com. 